\title{
Thrombo-Embolism Risk and Prophylaxis amongst Hospitalized Patients in Two Hospitals in Cameroon: A Cross-sectional Study in Sub-Saharan Africa
}

Hamadou $\mathrm{B}^{1,2 *}$, Kamdem $\mathrm{F}^{2}$, Bessong $\mathrm{H}^{1,3}$, Ndongo Amougou $\mathbf{S}^{1,4}$, Kuate Mfeukeu $\mathrm{L}^{1,2}$, Nganou $\mathrm{CN}^{1,2}$, Boombhi $\mathrm{J}^{1,5}$, Menanga $\mathrm{A}^{1,5}$ and Kingue $\mathrm{S}^{1,5}$ ${ }^{1}$ Department of Internal Medicine and Specialties, Faculty of Medicine and Biomedical Sciences, University of Yaoundé, Cameroon

${ }^{2}$ Cardiology Unit, Central Hospital of Yaoundé, Cameroon

${ }^{3}$ Faculty of Medicine and Pharmaceutical Sciences, University of Douala, Cameroon

${ }^{4}$ Cardiology Unit, University Teaching Hospital of Yaoundé, Cameroon

${ }^{5}$ Cardiology Unit, Medicine B, General Hospital of Yaoundé, Cameroon

\begin{abstract}
Background: Venous thrombo-embolism (VTE) is frequent worldwide. It has not been sufficiency studied in sub-Saharan Africa, with few data on the prevalence and treatment from urban settings.

Objectives: We sought to study the thromboembolic risk and rate of thrombo-prophylaxis for VTE in hospitalized patients.

Methods: Between November 2016 and April 2017, we carried out a cross-sectional descriptive study in two hospitals in the Far North region- Cameroon. Participants were consenting adult patients hospitalized in the medical and surgical wards. We excluded those with diagnosed VTE. We evaluated the risk for VTE with Caprini Risk Assessment model and we assessed prophylaxis measures used.
\end{abstract}

Results: A total of 520 patients were included - $282(54.2 \%)$ from the surgical units and $238(45.8 \%)$ from the medical units. The mean age was $49 \pm 17$ years, and $296(57 \%)$ were males. The mean duration of hospitalization was $10 \pm 9$ days. Risk for VTE was seen in $284(54.6 \%)$ patients $-182(64.5 \%)$ in the surgical units, and $102(42.8 \%)$ in the medical units $(\mathrm{p}<0.001)$. Of those at risk, $165(58.1 \%)$ were males. Adequate VTE thrombo-prophylaxis was carried out in $120(42.3 \%)$ patients - $86(47.3 \%)$ in the surgical units, and $33(32.4 \%)$ in the medical units.

Conclusion: The risk for VTE was seen in more than half of hospitalized patients in these semi-urban and rural hospitals. Less than half of those at risk received adequate thrombo-prophylaxis. The surgical units had significantly higher VTE risk and adequate prophylaxis rate than the medical units.

Keywords: Thromboembolism; Risk assessment; Prophylaxis; Cameroon; Sub-Saharan Africa

\section{Introduction}

Venous thrombo-embolism (VTE) involves deep venous thrombosis (DVT), with or without pulmonary embolism (PE)-the acute complication of DVT [1]. It is frequent worldwide, affecting 5 to $10 \%$ of the population [2]. The incidence is about 1 per 1000 annually in the adult population [3]. It is the third most common cardiovascular disease after acute coronary syndrome and stroke $[4,5]$. It is 100 times more likely to occur in hospitalised patients [6]. It is a common complication during and after hospitalisation for an acute medical illness or surgery. Most hospitalised patients have one or more risk factors for VTE, and around $60 \%$ of people undergoing major surgery will have a DVT [7]. In the absence of adequate thrombo-prophylaxis in acutely ill patients, 10 to $20 \%$ will develop a DVT [8]. This high risk is associated with low rates of adequate thrombo-prophylaxis worldwide $[9,10]$.

The burden of VTE has not been well characterized in Low-Middle Income (LMIC) settings, especially in sub-Saharan Africa (SSA) [11]. Few studies in tertiary urban hospitals have assessed the prevention and treatment of VTE $[12,13]$. The ENDORSE Africa study that assessed the risk factors and rate of thrombo-prophylaxis was conducted in urban hospitals [9]. But the burden and the rate of thrombo-prophylaxis for VTE is not known in rural areas of LMICs. These informations are needed to guide informed public health strategies. We carried out this cross-sectional descriptive study with the aim of assessing the thrombo-embolic risk, and the rate of thrombo-prophylaxis for VTE in hospitalized patients in two semi-urban and rural hospitals from Cameroon-SSA.

\section{Methods}

\section{Ethical considerations}

The institutional review board of the Faculty of Medicine and Biomedical sciences of the University of Yaounde 1 approved of this study. We carried out this study in accordance with the declarations of Helsinki [14]. We report this work according to the Standards for Reporting observational studies (STROBE) guidelines [15]. We adopted the ENDORSE methodology $[9,10]$ for this study.

\section{Study design and setting}

Between November 2016 and April 2017, author carried out this cross-sectional descriptive study in the surgical and medical units of two Hospitals in Maroua and Meskine- in the Far North region of Cameroon. Maroua is the regional capital of the region- Savannah

${ }^{*}$ Corresponding author: $\mathrm{Ba}$ Hamadou, MD, Department of Medicine and Specialties, Faculty of Medicine and Biomedical Sciences, University of Yaoundé, Cameroon, Tel: 237696416842; E-mail: drhamadouba@yahoo.fr

Received August 02, 2018; Accepted August 22, 2018; Published August 28, 2018

Citation: Hamadou B, Kamdem F, Bessong H, Ndongo Amougou S, Kuate Mfeukeu L, et al. (2018) Thrombo-Embolism Risk and Prophylaxis amongst Hospitalized Patients in Two Hospitals in Cameroon: A Cross-sectional Study in Sub-Saharan Africa. J Vasc Med Surg 6: 367. doi: 10.4172/2329-6925.1000365

Copyright: (c) 2018 Hamadou B, et al. This is an open-access article distributed under the terms of the Creative Commons Attribution License, which permits unrestricted use, distribution, and reproduction in any medium, provided the original author and source are credited. 
Citation: Hamadou B, Kamdem F, Bessong H, Ndongo Amougou S, Kuate Mfeukeu L, et al. (2018) Thrombo-Embolism Risk and Prophylaxis amongst Hospitalized Patients in Two Hospitals in Cameroon: A Cross-sectional Study in Sub-Saharan Africa. J Vasc Med Surg 6: 367. doi: 10.4172/2329-6925.1000367

Page 2 of 5

ecological zone. It is a semi-urban setting, with a regional Hospital that has a catchment population of about 3.5 million inhabitants. Meskine is a rural setting in the out-skirts of Maroua, with a large private Hospital. Both Hospitals received about 94.000 patients annually.

\section{Participants}

These were adults $\geq 18$ years of both sexes, who were hospitalized in the medical and surgical units of these Hospitals. We excluded those treated for Venous Thrombo-Embolic (VTE) disease.

\section{Variables}

We collected socio-demographic data (age, sex, level of education, monthly income, and marital status), risk factors for VTE (Classified according to the Caprini risk assessment model for VTE) [16], and prophylaxis measures for VTE (early ambulation, anti-thrombotic stockings, low molecular weight heparin, intermittent pneumatic compression, aspirin and vitamin $\mathrm{k}$ antagonist). We also measured their height $(\mathrm{m})$ and weight $(\mathrm{kg})$, to calculate their Body Mass Index (BMI).

\section{Procedure}

We prospectively recruited hospitalized patients from their bedsides. We interviewed consenting patients (French, English, or Dialect) to obtained socio-demographic data, and risk factors for VTE. We consulted their medical records to obtain data on the admission diagnoses, type of pharmacologic thrombo-prophylaxis according to the American College of Chest Physicians (ACCP) guidelines [8], and supplementary information on risk factors for VTE, and number of days of hospitalization, contra-indications for VTE prophylaxis. We measured their height in light clothing and no shoes to the nearest $0.1 \mathrm{~kg}$ with an electronic weighing device (Seven star ${ }^{\circledR}$ LCD display Germany). To measure the weight of bed ridden patients we used an electronic bed scale Wunder ${ }^{\circledR} \mathrm{pl}-250$, whereby the participants were placed supine, and their weights recorded to one decimal place in kilograms (kg). We measured their height with a stadiometer, with no shoes to the nearest $0.5 \mathrm{~cm}$. For bedridden patients, we used a measuring tape. The average of two measurements was recorded.

\section{Working definitions}

We used the Caprini risk assessment model for VTE derived from the ACCP $8^{\text {th }}$ edition risk criteria for VTE $[8,16]$. We classified risk factors in to: Low risk - Caprini score of 2, Moderate risk - Caprini score of 3-4, and High risk - Caprini score $\geq 5$. We defined appropriate VTE prophylaxis according to the ACCP guidelines [8].

Sample size : We used the Cochrane formula for cross-sectional studies to calculate the sample size [17]. With an expected proportion of $50.4 \%$ of VTE [9], and with a precision of $5 \%$, the estimated sample size was 384 participants.

\section{Statistical analysis}

We analyzed the data with the software IBM SPSS version 23.0. We have presented the quantitative variables as means $( \pm$ standard deviation), and qualitative variables as frequencies and proportions. We compared the risk factors for VTE and the thrombo-prophylaxis strategy between the surgical and medical units using the chi-squared test. We considered a $p$ value $<0.05$ to be statistically significant for the observed differences.

\section{Results}

\section{Participants and baseline characteristics}

We recruited a total of 520 patients, of whom 238 (45.8\%) were admitted in the medical units, and $282(54.2 \%)$ were admitted in the surgical units. Their mean age was $48.8 \pm 17$ years (Medical unit: $57.3 \pm 12.6$ years versus Surgical unit: $41.6 \pm 17$ years, $\mathrm{p}<0.001)$ and ranged from 18 to 90 years. There were 296 (57\%) males, and $224(43 \%)$ females. The socio-demographic characteristics are summarized in Table 1. Most of the patients were married, in their forties, self-employed, had no formal education, and earned less than 62 dollars monthly.

\section{Main results}

Assessing patients for VTE risk using the Caprini risk assessment model showed that 284 (54.4\%) patients were at risk for VTE-182 $(64.5 \%)$ in the surgical unit, and $102(42.8 \%)$ in the medical unit $(\mathrm{p}<0.001)$. The risk for VTE was seen in $165(55.7 \%)$ males, and 119 (53.1\%) females ( $\mathrm{p}=0.555)$. The VTE risk stratification is shown in Figure 1. Overall, most patients were at high risk for VTE especially in the surgical units. Table 2 shows the admission diagnoses of those at risk for VTE. Most patients in the medical units were admitted for neurological disorders, while most patients in the medical units were admitted for orthopedic disorders. The mean duration of hospitalization for those at risk of VTE was $11.9 \pm 10.6$ days (range: 4 to 98 days) - surgical unit: $13.8 \pm 10.9$ days, and medical unit: 8.7 \pm 9.3 days $(\mathrm{p}<0.001)$. Patients admitted in the medical units were older (mean age surgical unit: $44 \pm 17$ years, and mean age medical units: $60.5 \pm 13.7$ years, $\mathrm{p}<0.001)$.

\begin{tabular}{|c|c|c|}
\hline Variable & Frequency(n) & Percentage (\%) \\
\hline \multicolumn{3}{|l|}{ Age range(Years) } \\
\hline$\leq \mathbf{3 0}$ & 90 & 17.3 \\
\hline $31-40$ & 77 & 14.8 \\
\hline $41-50$ & 125 & 24 \\
\hline $51-60$ & 101 & 19.4 \\
\hline $61-70$ & 65 & 12.5 \\
\hline$>70$ & 62 & 11.9 \\
\hline \multicolumn{3}{|l|}{ Marital Status } \\
\hline Married & 342 & 65.8 \\
\hline Single & 80 & 15.4 \\
\hline Widow & 51 & 9.8 \\
\hline Divorced & 47 & 9 \\
\hline \multicolumn{3}{|l|}{ Employment status } \\
\hline Unemployed & 218 & 41.9 \\
\hline Self-employed & 239 & 46 \\
\hline Civil servant & 63 & 12.1 \\
\hline \multicolumn{3}{|c|}{ Monthly income(Dollars) } \\
\hline None & 218 & 41.9 \\
\hline$<62$ & 147 & 28.2 \\
\hline $62-123$ & 67 & 12.9 \\
\hline $123-185$ & 49 & 9.4 \\
\hline$>185$ & 39 & 7.5 \\
\hline \multicolumn{3}{|l|}{ Level of education } \\
\hline None & 262 & 50.4 \\
\hline Primary & 109 & 21 \\
\hline Secondary & 77 & 14.8 \\
\hline Tertiary & 73 & 13.8 \\
\hline
\end{tabular}

Table 1: Socio-demographic characteristics of the patients. 
Citation: Hamadou B, Kamdem F, Bessong H, Ndongo Amougou S, Kuate Mfeukeu L, et al. (2018) Thrombo-Embolism Risk and Prophylaxis amongst Hospitalized Patients in Two Hospitals in Cameroon: A Cross-sectional Study in Sub-Saharan Africa. J Vasc Med Surg 6: 367. doi: 10.4172/2329-6925.1000367

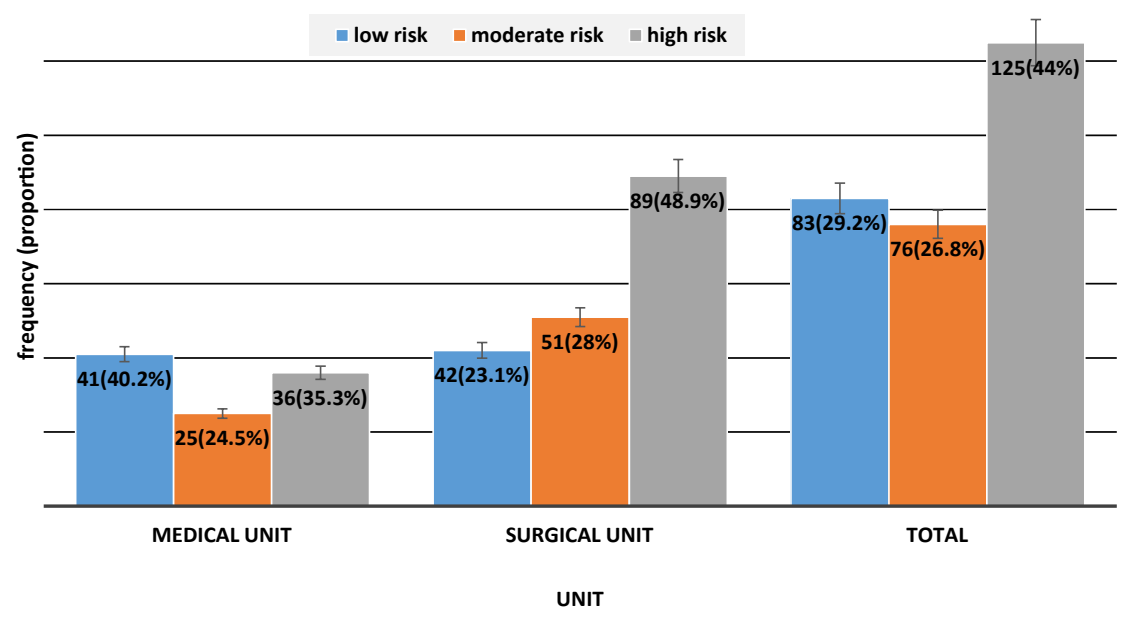

Figure 1: Risk stratification for Venous Thrombo-Embolism.

\begin{tabular}{|l|c|c|}
\hline Reasons for Hospitalization & Frequency(n) & Percentage (\%) \\
\hline Medical units(N=102) & & \\
\hline Neurological disease & 31 & 30.4 \\
\hline Pulmonary infection & 17 & 16.7 \\
\hline Acute heart failure & 18 & 17.6 \\
\hline Other Cardiovascular diseases & 8 & 7.8 \\
\hline Renal disease & 8 & 7.8 \\
\hline Metabolic disease & 7 & 6.9 \\
\hline Gastrointestinal disease & 7 & 6.9 \\
\hline Malignancy & 2 & 2.0 \\
\hline Hematologic disease & 2 & 2.0 \\
\hline Rheumatologic disease & 2 & 2.0 \\
\hline Surgical units(N=182) & & \\
\hline Orthopaedic surgery & 67 & 36.8 \\
\hline Gynaecological surgery & 38 & 20.9 \\
\hline Urological surgery & 20 & 11.0 \\
\hline Visceral Surgery & 19 & 10.4 \\
\hline Under observation in surgical units & 12 & 6.6 \\
\hline Awaiting elective surgery & 1 & 0.5 \\
\hline Admitted in neurosurgical unit & 12 & 6.6 \\
\hline Malignancy & 9 & 4.9 \\
\hline Metabolic disease & 4 & 2.2 \\
\hline
\end{tabular}

Table 2: Admission diagnoses of those at risk for Venous Thrombo-Embolism.

Table 3 shows the pre-admission and admission risk factors for VTE. The most frequent pre-admission risk factors were; prolonged immobility in 55 (19.4\%), obesity in 42 (14.8\%), and pregnancy within 3 months in $20(7 \%)$ patients. The most frequent risk factors during admission were; complete immobilization in $91(32 \%)$, and admitted to an Intensive Care Unit (ICU) in $26(9.2 \%)$ patients.

Figure 2 shows the pattern of anti-thrombotic prophylaxis. Of the 284 patients who were at risk for VTE, $120(42.3 \%)$ received appropriate thrombo-prophylaxis- Medical units: 33 (32.4\%), and Surgical units: $87(47.3 \%)(\mathrm{p}=0.015)$. Table 4 shows the thrombo-prophylaxis strategy used (adequate or in-adequate) according to the level of risk presented by the patients. Low molecular weight heparin (LMWH) was frequently used in both units. Table 5 shows the contra-indications to thromboprophylaxis in those at risk. Significant renal impairment was the most common reason for contraindication to anticoagulant therapy followed by intracranial hemorrhage and clinically relevant hepatic impairment.

\begin{tabular}{|l|c|c|c|c|}
\hline Risk factors & $\begin{array}{c}\text { Total, } \\
\mathbf{N}(\%)\end{array}$ & $\begin{array}{c}\text { Medical } \\
\text { unit, } \mathbf{n}(\%)\end{array}$ & $\begin{array}{c}\text { Surgical } \\
\text { unit, } \mathbf{n}(\%)\end{array}$ & $\boldsymbol{p}$ value \\
\hline Before hospitalisation & & & & \\
\hline Long term immobility & $55(19.4)$ & $26(25.5)$ & $29(15.9)$ & 0.049 \\
\hline Obesity & $42(14.8)$ & $19(18.6)$ & $23(12.6)$ & 0.171 \\
\hline Varicose veins & $6(2.1)$ & $3(2.9)$ & $3(1.6)$ & 0.460 \\
\hline Oral Contraceptives & $11(3.9)$ & $2(2.0)$ & $9(4.9)$ & 0.224 \\
\hline Previous VTE & $4(1.4)$ & $3(2.9)$ & $1(0.6)$ & 0.117 \\
\hline Pregnancy & $20(7.0)$ & $0(0.0)$ & $20(11.0)$ & 0.001 \\
\hline Chronic Pulmonary Disease & $7(2.5)$ & $7(6.9)$ & $0(0.0)$ & $<0.001$ \\
\hline Chronic Heart Failure & $9(3.2)$ & $9(8.8)$ & $0(0.0)$ & $<0.001$ \\
\hline Malignancy & $8(2.8)$ & $2(2.0)$ & $6(3.3)$ & 0.526 \\
\hline None & $122(43.0)$ & $31(30.4)$ & $91(50.0)$ & 0.001 \\
\hline During hospitalization & & & & \\
\hline Admitted to an ICU & $26(9.2)$ & $7(6.9)$ & $19(10.4)$ & 0.326 \\
\hline Mechanical ventilation & $10(3.5)$ & $6(5.9)$ & $4(2.2)$ & 0.105 \\
\hline Partial Immobilisation* & $25(8.8)$ & $13(12.7)$ & $12(6.6)$ & 0.082 \\
\hline Complete Immobilisation & $91(32.0)$ & $28(27.5)$ & $63(34.6)$ & 0.219 \\
\hline Cancer therapy & $13(4.6)$ & $4(3.9)$ & $9(4.9)$ & 0.698 \\
\hline None & $119(41.9)$ & $44(43.1)$ & $75(41.2)$ & 0.756 \\
\hline Imobilisan & & & & \\
\hline
\end{tabular}

*Immobilisation with bathroom privileges. ICU : Intensive Care Unit. VTE : Venous Thrombo-Embolism

Table 3: Pre-admission and Admission risk factors for Venous Thrombo-Embolism

\section{Discussion}

We carried out this cross-sectional descriptive study to assess the thrombo-embolic risk, and rate of thrombo-prophylaxis for VTE in hospitalized patients in two semi-urban and rural hospitals in the Far North region (Savannah ecological zone) of Cameroon. The risk for VTE was seen in more than half of hospitalized patients in these semi-urban and rural hospitals. Less than half of those at risk received adequate thrombo-prophylaxis. The surgical units had significantly higher VTE risk and adequate prophylaxis rate than the medical units. This high risk and low thrombo-prophylaxis was seen in poor and unemployed patients at the prime of their age ( 40 to 50 years), with less formal education.

The high risk burden and low rates of adequate thrombo-prophylaxis for VTE in this semi-urban and rural hospitals is comparable to that reported in urban tertiary hospitals in Africa and beyond [9-11,18]. This is however associated with high rates of younger age groups, 
Citation: Hamadou B, Kamdem F, Bessong H, Ndongo Amougou S, Kuate Mfeukeu L, et al. (2018) Thrombo-Embolism Risk and Prophylaxis amongst Hospitalized Patients in Two Hospitals in Cameroon: A Cross-sectional Study in Sub-Saharan Africa. J Vasc Med Surg 6: 367. doi: 10.4172/2329-6925.1000367

Page 4 of 5

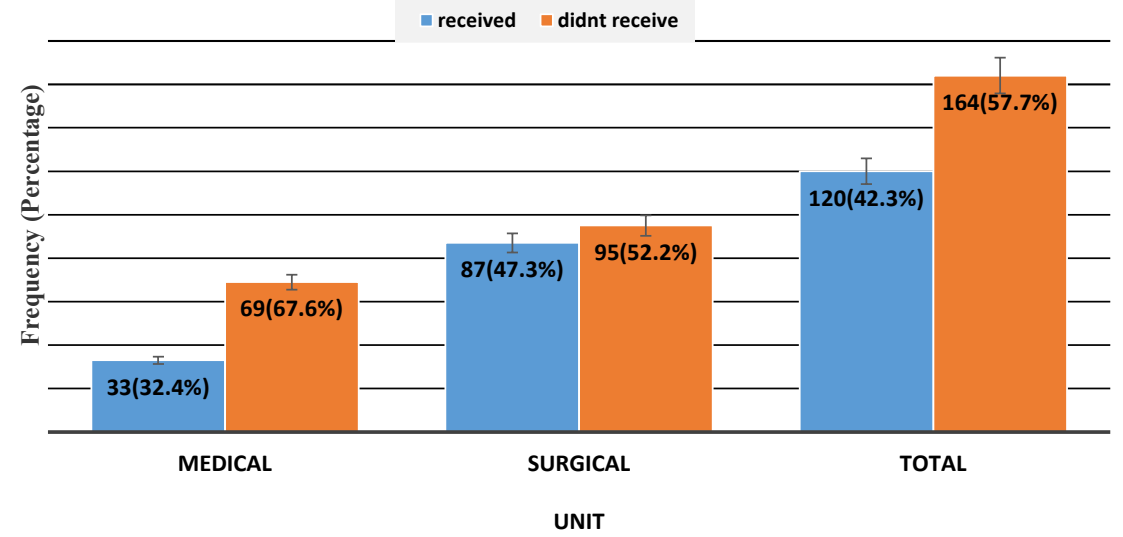

Figure 2: Adequate prophylaxis strategy for Venous Thrombo-Embolism.

\begin{tabular}{|c|c|c|c|c|}
\hline Prophylaxis & Total, $\mathbf{N}(\%)$ & Medical unit, n(\%) & Surgical unit, n(\%) & $p$ value \\
\hline Adequate & $N=120$ & $n=33$ & $n=87$ & \\
\hline LMWH & $52(43.3)$ & $17(51.5)$ & $35(40.2)$ & 0.265 \\
\hline Early ambulation & $46(38.3)$ & $1(3.0)$ & $45(51.7)$ & $<0.001$ \\
\hline GCS & $22(18.3)$ & $15(45.5)$ & $7(8.0)$ & $<0.001$ \\
\hline In-adequate & $\mathrm{N}=34$ & $n=5$ & $\mathrm{n}=29$ & \\
\hline Aspirin & $29(85.3)$ & $2(40)$ & $27(93.1)$ & 0.002 \\
\hline Early Ambulation & $2(5.9)$ & $1(20)$ & $1(3.4)$ & 0.144 \\
\hline VKA & $1(2.9)$ & $0(0)$ & $1(3.4)$ & 0.676 \\
\hline GCS & $2(5.9)$ & $2(40)$ & $0(0)$ & 0.0004 \\
\hline
\end{tabular}

Table 4: Adequate and In-Adequate Thrombo-prophylaxis used.

\begin{tabular}{|c|c|c|c|c|}
\hline Risk factor before hospitalization & Overall, N(\%) & Medical unit, $n(\%)$ & Surgical unit, $n(\%)$ & $p$ value \\
\hline Significant renal impairment & $12(4.2)$ & $8(7.8)$ & $4(2.2)$ & 0.024 \\
\hline Low platelet count & $1(0.4)$ & $1(1)$ & $0(0)$ & 0.177 \\
\hline Aspirin use & $3(1.1)$ & $0(0)$ & $3(1.7)$ & 0.186 \\
\hline Non-steroidal anti-inflammatory Drugs & $6(2.1)$ & $1(1)$ & $5(2.8)$ & 0.316 \\
\hline Intracranial hemorrhage & $11(3.9)$ & $6(5.9)$ & $5(2.8)$ & 0.196 \\
\hline Clinically relevant hepatic impairment & $7(2.5)$ & $7(6.9)$ & $0(0)$ & $<0.001$ \\
\hline None & $244(85.9)$ & $79(77.5)$ & $165(90.7)$ & 0.001 \\
\hline
\end{tabular}

Table 5: Contra-indications to Thrombo-Prophylaxis in those at Risk.

unemployment, poverty and low level of education in this semiurban and rural population. This combination has significant health and economic implications. Besides the increase in the morbidity, the mortality is expected to be higher due to the low purchasing power of the patients, the poorly equiped hospitals (consumables, materials, and personnel), and poor health system (no health coverage). The exact burden of VTE is not known in this setting, as it may go undiagnosed and under-reported [11]. It is a disease condition that is largely underdiagnosed and under-treated despite the very high disease burden in hospitalized patients worldwide [6]. Up to $60 \%$ of patients undergoing surgery will have VTE, and 10 to $20 \%$ of patients with an acute illness will have VTE $[7,8]$. Looking at the risk category, most of the patients had high risk for VTE. Thus, the burden of VTE is expected to be higher (more than 20\%) in patients with an acute illness in this setting. This can go undiagnosed as it is often asymptomatic, or present as prolong fever mimicking an infectious process, or presents as sudden death from fatal pulmonary embolism [19]. The economic burden is expected to be high as most patients at high risk are young and potentially productive. This stress the need for adequate thrombo-prophylaxis in these settings.
Patients admitted in the medical unit were significantly older than those admitted in the surgical unit. This age pattern was similarly reported in other studies $[9,10,18]$. However, patients in this study were younger in both units compared to that reported by other authors $[9,10,18]$. We included patients from the medical units as young as 18 years compared to 40 years in other reports. Patients in the medical units were admitted for complications of chronic conditions like hypertension, which comes with age, while patients admitted in the surgical units have more acute conditions like trauma. Neurological disorders-mainly stroke syndromes, were the most frequent reasons for admission in the medical units, followed by chronic heart failure. This is consistent with other reports $[9,10,18]$. The pattern of admission in the surgical unit was quite different from other reports in the urban settings. Even-though orthopaedic surgery cases were frequent, most of the cases were trauma related from armed conflicts (terrorist attacks), and motorcycle accidents (frequent mode of transportation). Patients admitted in the surgical units had significantly higher rates of risk for VTE. This trend has been reported in the urban settings. The spectrum of disease is different between the units. Overall, the rate of risk for 
Citation: Hamadou B, Kamdem F, Bessong H, Ndongo Amougou S, Kuate Mfeukeu L, et al. (2018) Thrombo-Embolism Risk and Prophylaxis amongst Hospitalized Patients in Two Hospitals in Cameroon: A Cross-sectional Study in Sub-Saharan Africa. J Vasc Med Surg 6: 367. doi: 10.4172/2329-6925.1000367

Page 5 of 5

VTE was slightly higher in the semi-urban and rural settings than in the urban settings. Cohen et al. [10] reported $51.8 \%$ of patients at risk, and Kingue et al. [9] reported 51.2\%, and Goubran et al. [18] reported $39.2 \%$. The higher rate of risk for VTE in the surgical units was associated with a higher rate of adequate thrombo-prophylaxis. This trend is consistent with other reports from the urban settings $[9,10,18]$. As suggested by other authors, the benefits of thrombo-prophylaxis in surgical patients has long been recognized. The risk assessment for VTE is much more easier in the surgical units, as this depends on the type of surgery. The risk assessment in the medical units depends on an array of diseases and risk factors. Also, the main drivers of underuse of adequate thrombo-prophylaxis were due to medical conditions such as significant renal and liver impairment. This trend is similar to that reported by other authors [9].

\section{Limitations}

Our findings should be considered in the light of some limitations due to the cross-sectional design. We assessed the use of thromboprophylaxis, but it was difficult to ascertain the quality in the short term-how many people were event free. Our findings could be overestimates of adequate thrombo-prophylaxis in this setting.

We could not assess the burden of the genetic pre-dispositions to VTE due to technical and financial constraints. Despite these limitations, this is the first study of its kind in this setting. We prospectively collected data mainly through clinical evaluation at the bedside of patients, thus ensuring high data quality. The two hospitals involved in the study are the main hospitals in the region. This study might reflect best practice in the region.

\section{Conclusion}

The risk for VTE was seen in more than half of hospitalized patients in these semi-urban and rural hospitals. Less than half of those at risk received adequate thrombo-prophylaxis. The surgical units had significantly higher VTE risk and adequate prophylaxis rate than the medical units. This high risk and low thromboprophylaxis was seen in poor patients, with less formal education. In order to reduce morbidity and mortality associated with VTE in low-income settings, there is a need to continuously empower the healthcare personnel in assessing the risk for VTE, and to use adequate thrombo-prophylaxis strategies. There is also the need to strengthen health system by ensuring the constant supply of lowmolecular weight heparin, and graduated compression stockings at affordable prices.

\section{Addendum}

B Hamadou, F Kamdem, H Bessong, S Ndongo Amougou, L Kuate Mfeukeu contributed to the study concept and protocol. Hamadou, F Kamdem, $\mathrm{H}$ Bessong and $\mathrm{S}$ Kingue performed statistical analyses. H Bessong, CN Nganou, J Boombhi, A Menanga contributed to data acquisition. H Bessong, S Ndongo Amougou, L Kuate Mfeukeu, CN Nganou, J Boombhi, A Menanga and S Kingue analyzed and interpreted data. B Hamadou, F Kamdem, H Bessong drafted the final manuscript. All the authors approved of the final draft to be published.

\section{Acknowledgement}

We thank Dr. Ahmadou Musa Jingi (MD, DES Internal Medicine) for critically reviewing this work.

\section{References}

1. Goldhaber SZ, Bounameaux H (2012) Pulmonary embolism and deep vein thrombosis. Lancet 379: 1835-1846.

2. Zakai NA, McClure LA (2011) Racial differences in venous thromboembolism J Thromb Haemost 9: 1877-1882.

3. White RH (2003) The epidemiology of venous thromboembolism. Circulation 107: $1-4$.

4. Lindblad B, Eriksson A, Bergqvist D (1991) Autopsy-verified pulmonary embolism in a surgical department: analysis of the period from 1951 to 1988 Br J Surg 78: 849-852.

5. Sandler DA, Martin JF (1989) Autopsy proven pulmonary embolism in hospita patients: are we detecting enough deep vein thrombosis? J R Soc Med 82: 203-205.

6. Beckman MG, Hooper WC, Critchley SE, Ortel TL (2010) Venous thromboembolism: a public health concern. Am J Prev Med 38: 495-501.

7. Ageno W, Agnelli G, Imberti D, Moia M, Palareti G, et al. (2008) Risk factors for venous thromboembolism in the elderly: results of the master registry. Blood Coagul Fibrinolysis 19: 663-667.

8. Geerts WH, Bergqvist D, Pineo GF, Heit JA, Samama CM, et al. (2008) Prevention of venous thromboembolism: American College of Chest Physicians evidence-based clinical practice guidelines (8th Edition). Chest $J$ 133: 381S-453S

9. Kingue S, Bakilo L, Mvuala R, Pay EP, Minkande JZ, et al. (2014) Epidemiologica African day for evaluation of patients at risk of venous thrombosis in acute hospital care settings: cardiovascular topic. Cardiovasc J Afr 25: 159-164.

10. Cohen AT, Tapson VF, Bergmann JF, Goldhaber SZ, Kakkar AK, et al. (2008) Venous thromboembolism risk and prophylaxis in the acute hospital care setting (ENDORSE study): A multinational cross-sectional study. The lancet 371: 387-394.

11. Danwang C, Temgoua MN, Agbor VN, Tankeu AT, Noubiap JJ (2017) Epidemiology of venous thromboembolism in Africa: a systematic review. J Thromb Haemost 15: 1770-1781.

12. Abah JP, Menanga A, Ngahane BHM, Minkande JZ, Akono MN, et al. (2016) Pattern of venous thromboembolic diseases in a resources-limited setting in Cameroon. Pan Afr Med J 23: 236.

13. Kingue S, Tagny-Zukam D, Binam F, Nouedoui C, Teyang A, et al. (2002) Venous Thrombo-embolic disease in Cameroon. (A series of 18 cases) Médecine Trop 62: 47-50.

14. World Medical Association declaration of Helsinki (1997) Recommendations guiding physicians in biomedical research involving human subjects. JAMA 277: 925-926.

15. Von Elm E, Altman DG, Egger M, Pocock SJ, Gøtzsche PC, et al. (2007) The Strengthening the Reporting of Observational Studies in Epidemiology (STROBE) statement: guidelines for reporting observational studies. Bull World Health Organ 85: 867-872.

16. Caprini JA (2005) Thrombosis risk assessment as a guide to quality patien care. Dis Mon 51: 70-78.

17. Charan J, Biswas T (2013) How to calculate sample size for different study designs in medical research? Indian J Psychol Med 35: 121-126.

18. Goubran HA, Sholkamy S, El-Haddad A, Mahmoud A, Rizkallah MA, et al (2012) Venous thromboembolism risk and prophylaxis in the acute hospital care setting: report from the ENDORSE study in Egypt. Thromb J 10: 20.

19. Stein PD, Henry JW (1995) Prevalence of acute pulmonary embolism among patients in a general hospital and at autopsy. Chest 108: 978-981. 